|EDITORIAL|

\title{
Pluralidades em Saúde: análises lusófonas
}

\author{
Health pluralities: lusophone analyzes
}

\author{
Estélio Gomberg ${ }^{1}$ \\ Ana Cristina de Souza Mandarino ${ }^{2}$ \\ Izamara Bastos Machado ${ }^{3}$ \\ ${ }^{1}$ Universidade Estadual de Santa Cruz. Ilhéus/BA, Brasil. \\ ${ }^{2}$ Universidade Federal de Sergipe. Lagarto/SE, Brasil. \\ ${ }^{3}$ Fundação Oswaldo Cruz. Rio de Janeiro/RJ, Brasil.
}

Em diversos contextos históricos, registraram-se interesses de constituição de uma comunidade lusófona como mecanismo legitimador de uma identidade-unidade constituída por países de distintos continentes, colonizados por Portugal. Ao longo do tempo, desafios foram sendo colocados em suas agendas, desencadeando novas formas de integrações em diversos setores da sociedade, incluindo, o campo da saúde.

A motivação deste dossiê "Pluralidades em Saúde: análises lusófonas" ratifica as atenções preconizadas por agências internacionais no pensar e agir na saúde sem fronteiras. Compreendendo o processo de globalização articulado com expressões locais de sistemas terapêuticos, visando à integralidade para resolutividade de demandas no processo saúde-doença às suas historicidades e às suas complexidades em instituições e grupos sociais.

O interesse em reunir artigos de pesquisadores de países lusófonos também se coloca na consolidação de parcerias interinstitucionais, iniciadas no Grupo de Trabalho "Promoção de Saúde e Desenvolvimento Sustentável", do XI Congresso Luso-Afro-Brasileiro de Ciências Sociais, ocorrido em 2011, na Cidade de Salvador/Bahia, Brasil. E, posteriormente, com ações técnico-científicas de diversas naturezas, envolvendo profissionais de diferentes áreas de conhecimento que estabeleçam diálogos com o campo da saúde.

Discorrer sobre a importância da organização de redes de cooperação entre países lusófonos no campo da saúde é o tema do artigo de Lima et al. ${ }^{1}$, expondo a experiência exitosa na informação e na formação de promoção da saúde entre a Fundação Oswaldo Cruz, Brasil e Universidade do Minho, Portugal, e se conclui que a cooperação é estratégica para as manifestações de acesso aberto de conhecimentos para públicos distintos. 
O artigo de Pereira et al. ${ }^{2}$ focaliza perfis de profissionais e de clínicas odontológicas na rede social Facebook, privilegiando diretrizes éticas dos Código de Ética Odontológico e pelo Código de Defesa do Consumidor, em que se verificaram diversas infrações de distintas naturezas, surgindo assim a recomendação para a atenção desses órgãos diante dos usos das redes sociais nas práticas profissionais.

As autoras Kalil e Aguiar ${ }^{3}$ atentam para as produções de discursos em materiais institucionais do Ministério de Saúde do Brasil referente ao aleitamento materno aos diversos atores sociais envolvidos, sustentando na teoria da enunciação de Émille Benveniste e de Eliseo Verón, respectivamente, sobre constituição das falas e o discurso da ilusão da verdade, objetivando as construções das posições de sujeito e relações de poder entre Estado e os sujeitos sociais envolvidos.

Uma reflexão teórica sobre as diversas dimensões do abortamento no Brasil sob a ótica do Princípio Fundamental da Dignidade Humana, em sua perspectiva constitucional, é a proposta do artigo de Lins, Lins e Vasconcelos ${ }^{4}$. Nesse artigo os autores apresentam dados estatísticos de estudos prévios e indicadores institucionais, concluindo que as diversas dimensões sociais pautam o ato e o reforço do respeito à dignidade humana e o direito à saúde.

Também o debate sobre aborto é realizado no artigo de Milanez et al. ${ }^{5}$. Privilegiando o itinerário terapêutico como método de investigação com mulheres que provocam o aborto em diversos contextos, os autores apontam a necessidade da proteção do sistema de saúde e da compreensão das vulnerabilidades sociais registradas nesse grupo social.

Ventura e Chaves ${ }^{6}$ analisam, por meio de dados institucionais, os processos de saúde mental em Angola, país com exposições de populações urbanas e rurais à guerra civil e a eventos traumáticos; atentando para a distinção dos processos saúde-doença nas distintas populações, associadas ao grau crescente de traumatização, ansiedade e depressão. Apesar de os conflitos terem se encerrados há quase 20 anos, foi verificada a urgente necessidade de ações governamentais e não governamentais para amenizações desses indicadores.

Nascimento e Fontes? , no artigo "Saúde Mental, Estigma e Experiência de Enfrentamento do Sofrimento: a Terapia Comunitária em uma comunidade do Recife", apreendem as expressões da terapia comunitária, em Pernambuco, Brasil, como ferramenta de fortalecimento de laços afetivos para os enfrentamentos e impactos na equalização do status social, da aproximação e da participação. Os autores revelam que a Terapia Comunitária é um espaço de desconstrução da imagem social do louco.

O artigo de Freitas e Meneguzzo 8 reflete sobre mudanças nos sistemas de saúde de Portugal e da Itália a partir da Troika, apreendendo novas lógicas de justificação, em que a credibilidade se torna elemento motriz nos novos contratos entre Estados. A partir de análise documental de matérias jornalísticas e de estudos de casos diversos, os autores concluem seu artigo, demonstrando com os respectivos apontamentos, os privilégios dos "países financiadores em detrimento dos interesses dos cidadãos dos países em recessão econômica".

O artigo de Tavares?, "Saúde e desigualdades sociais: um tema revisitado a partir de uma investigação empírica", busca rememorar o tema das desigualdades sociais em saúde nas últimas três décadas, focando o Município de Loures, situado na Área Metropolitana de Lisboa. O autor procura ofertar apontamentos sobre as assimetrias entre as classes sociais e diversos fatores envolvidos nos serviços de saúde dos setores público e privado, servindo desta forma como ferramenta importante para a implementação de linhas de intervenção social e promoção de saúde para equidade social.

Os "Terreiros de Candomblé das Cidades do Rio de Janeiro e de Salvador" são os espaços de reflexão de Mandarino, Gomberg e Machado ${ }^{10}$. Os autores reconhecem esses locais como espaços onde são executadas atividades de promoção de saúde, que envolvem racionalidades biomédicas e religiosas. Além disso, destacam que são espaços que ofertam serviços de cura para sujeitos, - adeptos e não adeptos dessa religião - e que devem ser reconhecidos como 
estratégia de legitimidade social na sociedade brasileira, assim como de práticas comunicativas que reforcem cada vez mais seus lugares de fala, em que são reafirmadas suas ancestralidades e suas experiências exitosas perante as comunidades.

Também na abordagem de serviços de saúde não estatal, o artigo de Carvalho e Afonso ${ }^{11}$ focaliza o acesso de mulheres de Angola, Moçambique e Guiné-Bissau aos diversos sujeitos que ofertam esses serviços no âmbito privado, concluindo, a partir das particularidades dos países estudados e nas estratégias do grupo social em questão, a eficácia do programa da redução da mortalidade em menores de cinco anos como um dos Objetivos de Desenvolvimento do Milênio.

Somando ao debate da saúde da mulher, o artigo de Schein et al. ${ }^{12}$, intitulado "Atenção á saúde da mulher vítima de violência: um recorte temporal", aponta para uma revisão sistemática sobre assistências dos serviços públicos de saúde no Brasil à mulher vítima de violência. Elencada nas bases de dados do Scientific Electronic Library Online e da Literatura Latino-Americana e do Caribe em Ciências da Saúde, aponta para a necessidade de organizações de ações de prevenção e promoção de saúde da mulher, englobando os diversos sujeitos envolvidos para a desnaturalização da violência e do papel da mulher na sociedade.

$\mathrm{O}$ artigo de Delaunay ${ }^{13}$ discorre sobre as diversas dimensões da procriação medicamente assistida (PMA) no que tange à doação de gametas. Estruturado em narrativas de sujeitos envolvidos nessa ação, com expressões do privadopúblico, trazem cena, com uma perspectiva inovadora, diversos conceitos interdisciplinares, envolvidos nesse processo.

Garioli et al. ${ }^{14}$ reflete sobre os desafios da maternidade em adolescentes, no estado do Espírito Santo no artigo "Protagonistas de uma história real: a experiência da maternidade adolescente em uma região interiorana brasileira". A partir de entrevistas com dez mães adolescentes, os autores aplicaram a técnica da análise de conteúdo, com enfoque em análise temática para compreender qual o significado da maternidade para essas adolescentes. De acordo com o estudo, os resultados enfatizam os aspectos do sentimento de ser mãe, as fortes mudanças na trajetória de vida, os apoios e os arrependimentos da gravidez precoce, e conclui discutindo sobre as atenções amplas da promoção da saúde sexual e reprodutiva do adolescente e as tensões de ser mãe na adolescência.

A identificação de padrões de mortalidade e perfis de saúde de homens e de mulheres acima de cinquenta anos, por meio do Inquérito Nacional de Saúde, de Portugal, foi o objetivo do artigo de Fernandes e Burnay ${ }^{15}$, com discrepâncias entre os gêneros, associadas a fatores de escolaridades e de rendimentos, demonstrando que os dados apresentados contribuem para explicar a distinção da qualidade de vida e do processo de envelhecimento de homens e mulheres.

Prezado leitor, desejamos a você boas leituras e esperamos que os textos e seus respectivos autores possam suscitar interesses por novas investigações. Também desejamos que os artigos proporcionem incrementações de novas abordagens, enfatizando processos de saúde-doença e reforçando as interfaces nos países lusófonos, especialmente, na formação em saúde.

\section{REFERÊNCIAS}

1. Lima NT et al. Informação e acesso ao conhecimento na cooperação entre países lusófonos. Rev. Bras. Pesq. Saúde. 2019; 21: (2): 144-154.

2. Pereira IT, et al. A ética no Facebook: um desafio contemporâneo para a Odontologia. Rev. Bras. Pesq. Saúde. 2019; 21(2): 115-122.

3. Kalil IR, Aguiar AC. "Amamentar hoje é pensar no futuro": o lugar da mulher nos discursos de promoção ao aleitamento materno contemporâneos. Rev. Bras. Pesq. Saúde. 2019; 21(2): 29-39. 
4. Lins-Kusterer L, Lins M, Vasconcelos C. Aborto: atenção humanizada e aspectos legais. Rev. Bras. Pesq. Saúde. 2019; 21(2): 40-50.

5. Milanez N, Emmerich AO, Martinelli KG, Esposti CDD. A decisão do aborto: itinerários, práticas e confidências. Rev. Bras. Pesq. Saúde. 2019; 21(2): 105-114.

6. Ventura M, Chaves J. Saúde mental: um estudo sobre transtorno de stress pós-traumático, ansiedade e depressão nas zonas rurais e urbanas do Sul de Angola. Rev. Bras. Pesq. Saúde. 2019; 21(2): 51-57.

7. Nascimento ABM, Fontes BAS. Saúde Mental, Estigma e Experiência de Enfrentamento do Sofrimento: a Terapia Comunitária em uma comunidade do Recife. Rev. Bras. Pesq. Saúde. 2019; 21(2): 155-164.

8. Freitas M, Meneguzzo M. Crise e legitimação: estudo dos Regimes de Justificação aplicados ao campo da Saúde. Rev. Bras. Pesq. Saúde. 2019; 21(2): 58-66.

9. Tavares D. Saúde e desigualdades sociais: um tema revisitado a partir de uma investigação empírica. Rev. Bras. Pesq. Saúde. 2019; 21(2): 8-16.

10. Mandarino CS, Gomberg E, Machado IB. Conexões entre Terreiros de Candomblé, Agências Sociais e Saúde. Rev. Bras. Pesq. Saúde. 2019; 21(2): 134-143.

11. Carvalho C, Afonso A. Gênero e pluralismo terapêutico:o acesso das mulheres ao sistema de saúde não estatal em Guiné-Bissau, Angola e Moçambique. Rev. Bras. Pesq. Saúde. 2019; 21(2): 67-75.

12. Schein S, Ubessi LD, Boeckel M, Prati LE. Atenção à saúde da mulher vítima de violência: um recorte temporal. Rev. Bras. Pesq. Saúde. 2019; 21(2): 174-185.

13. Delaunay C. Análise das tensões intrínsecas ao dispositivo de Procriação Medicamente Assistida com doação de gâmetas sob o olhar da Sociologia Pragmática. Rev. Bras. Pesq. Saúde. 2019; 21(2): 76-92.

14. Garioli DK, Martinelli KG, Esposti CDD, Emmerich AO. Protagonistas de uma história real: a experiência da maternidade adolescente em uma região interiorana brasileira. Rev. Bras. Pesq. Saúde. 2019; 21(2): 93-104.

15. Fernandes AA, Burnay R. Homens saudáveis, mulheres doentes? Um estudo sobre a esperança de vida e a saúde da população portuguesa. Rev. Bras. Pesq. Saúde. 2019; 21(2): 17-28. 